\title{
Aproximación Neurodinámica a la Cognición Social*
}

Neurodynamics Approach to Social Cognition

DOI: $10.11144 /$ Javeriana.upsy15-5.ancs

Recepción: 25 Agosto 2016 | Aprobación: 08 Diciembre 2016

\author{
Diego A. León Rodríguez ${ }^{a}$ \\ Universidad de los Andes, Colombia \\ FERNANDO CÁRDENAS \\ Universidad de los Andes, Colombia
}

aE-mail: da.leon10@uniandes.edu.co

Para citar este artículo: León Rodriguez, D., \& Cardenas, F. P. (2016). Aproximación Neurodinámica a la Cognición Social. Universitas Psychologica, 15(5). http://dx.doi.org/10.11144/Javeriana.upsy15-5.ancs

\section{RESUMEN}

En las últimas décadas ha crecido el estudio los mecanismos involucrados en el comportamiento social, gran parte de estas indagaciones se han realizado desde una aproximación de la neurociencia social cognitiva, la cual se basa en un modelo representacional del procesamiento de información. No obstante, esta aproximación ha sido ampliamente criticada por desconocer la participación del cuerpo, la dinámica afectiva, el contexto social, el cambio durante el desarrollo y suponer un procesamiento modular endógeno. En este sentido, este artículo presenta un modelo neurodinámico de la cognición social (CS), comprendiéndola desde una aproximación enactiva, situada, relacional y sistémica. Desde este modelo se describen los principales cambios en esperados la actividad cerebral durante las interacciones sociales en tiempo real y durante la ontogenia. Se concluye resaltando los desafíos y oportunidades que este tipo de aproximaciones puede proporcionar a la neurociencia y psicología social del futuro.

\section{Palabras clave}

Cognición social; cognición enactiva; desarrollo social; neurociencia social; neurodinámica.

\footnotetext{
ABSTRACT

In recent decades it has seen a growing interest to study the mechanisms involved in social behavior, much of these inquiries fall within social cognitive neuroscience approach, which is based on a representational model of information processing. However, this approach has been widely criticized for ignoring the body participation, emotional dynamics, social context, developmental changes and assuming an endogenous modular processing. In this regard, this article presents a neurodynamic model of social cognition, which understand social process from an enactive, embodied, situated, relational and systemic perspective. This model let us described the main expected changes in brain activity during ongoing social interactions and ontogeny. The conclusion highlights the challenges and opportunities that this kind of approach can provide for a coming neuroscience and social psychology.

Keywords

Enactive cognition; neurodynamic; social cognition; social development; social neuroscience.
} 


\section{Introducción}

El propósito de este escrito es proponer un modelo de la cognición social basado en una postura dinámica, enactiva y del desarrollo, con este modelo se tratará de dar sentido a los hallazgos que se han hecho en las últimas décadas desde la neurociencia social. La CS puede concebirse como una variedad de procesos psicológicos y biológicos que permiten detectar $y$ atribuir sentido intencional y afectivo a las señales provenientes de otros (Eisenberg, 2013; León, 2013; Rushworth, Mars, \& Sallet, 2013), estos procesos incluyen fenómenos como la percepción de señales corporales, el conocimiento implícito y explícito sobre los estados mentales propios y ajenos, la formación y mantenimiento de vínculos afectivos, la formación de actitudes, la moralidad, entre otros (Frith \& Frith, 2012; Grande-García, 2009). Desde finales del siglo XX las neurociencias se han enfocado en comprender los mecanismos neurobiológicos asociados a estos procesos (Adolphs, 2001; Cacioppo \& Bernston, 2002; Harmon-Jones \& Winkielman, 2007; Pelphrey, Adolphs, \& Morris, 2004), en especial, mediante el uso de imágenes cerebrales (Fiske \& Tailor, 2008; Lieberman, 2007a, 2007b).

Los principales modelos teóricos sobre la CS (Adolph, 1999 y 2001; Heberlein y Adolph, 2005) se fundamentan a una postura informacional que asume la CS como un grupo de procesos cómputo de representaciones sobre los demás (Beer \& Ochsner, 2006; Wiltshire et al., 2015). En estas aproximaciones la CS suele explicarse desde modelos lineales, donde el procesamiento social es llevado a cabo por módulos cerebrales innatos que han sido seleccionados ancestralmente, los cuales computan y representan la información social (Adolph, 2003; Lieberman, 2006, 2010). Al conjunto de estos módulos, se les llegó a conocer como cerebro social (Adolph, 2009; Isel \& Fernand, 2004; Frith \& Frith, 2012). Estas posturas han sido criticadas por sobre-simplificar la complejidad de la CS, del funcionamiento encefálico y del desarrollo humano, ya que suelen subestimar la importancia del contexto, la dependencia temporal y el carácter relacional.

En la última década han tomado fuerza las aproximaciones interaccionistas apoyadas en teorías de la cognición enactiva, corporizada, ecológica y en los sistemas dinámicos (Wiltshire et al., 2015). Desde la enacción la CS es a la vez percepción y acción en un cuerpo vivo situado, donde los procesos nerviosos se arraigan en un cuerpo incrustado en un mundo de interacciones sociales (De Jaegher \& Di Paolo, 2007; De Jaegher, Di Paolo \& Gallagher, 2010; Goldman \& de Vignemont, 2009). En este sentido, tanto destrezas sociales como circuitos neurales se forman mutuamente en un proceso de co-desarrollo, el cual ocurre a través de acoplamientos a múltiples niveles espaciotemporales (Di Paolo \& De Jaegher, 2012). La teoría de sistemas dinámicos complejos permite comprender cómo estos sistemas van cambiando su comportamiento a través del tiempo, un sistema dinámico tiene tres características principales: 1) está compuesto por una gran cantidad de componentes que interactúan entre sí de forma compleja (no-linear), es decir, el comportamiento del sistema no puede ser predicho desde la suma de los comportamientos individuales de sus componentes; 2) hay emergencia en las propiedades del sistema; y 3 ) el comportamiento emergente es auto-organizado, ya que no depende únicamente de las condiciones internas o externas, sino que es el resultado de acoplamientos complejos entre diferentes niveles de organización en un proceso de causalidad circular (Richardson, Dale, \& Marsh, 2014).

A continuación, se fundamentará empírica y teóricamente un nuevo modelo para comprender la CS, el cual toma como eje articulador las propuestas de los sistemas dinámicos, la enacción, y el desarrollo ontogenético. Con este modelo se busca explicar la emergencia de algunas habilidades sociales, la emergencia de estas habilidades durante la ontogenia depende de la organización de ciertos sistemas socio-afectivos, los cuales están estrechamente relacionados al desarrollo de ensamblajes neurales, patrones de actividad encefálica y 
cambios en las relaciones sociales (Barrett \& Satpute, 2013). En el modelo, se contemplan cuatro categorías, las cuales permiten agrupar los sistemas socio-afectivos y dar sentido al cambio que sucede durante las interacciones sociales y la ontogenia (Tabla 1). A partir de este punto se van a describir cada una de las categorías intentando clarificar los componentes neurodinámicos que las caracterizan.

\section{TABLA 1}

Resumen de las principales categorías en las que se agrupan los procesos de la cognición social

\begin{tabular}{|c|c|c|}
\hline Categorías & Sistemas Socio-Afectivos & $\begin{array}{c}\text { Habilidades Sociales } \\
\end{array}$ \\
\hline \multirow{2}{*}{$\begin{array}{l}\text { Percepción- } \\
\text { Acción }\end{array}$} & Mapeo Somático & $\begin{array}{l}\text { Construcción de imágenes somáticas sobre las señales } \\
\text { sociales (ojos, rostros, cuerpos, olores, sonidos) }\end{array}$ \\
\hline & $\begin{array}{l}\text { Resonadores sensoriomotores } \\
\text { somáticos }\end{array}$ & $\begin{array}{l}\text { Imitación, comunicación no verbal automática, } \\
\text { sintonización, aprendizaje vicario. }\end{array}$ \\
\hline \multirow{3}{*}{ Afectivos } & Mapas Viscerales & Generación de valor afectivo (apetitivo vs aversivo) \\
\hline & Resonadores Afectivos & Contagio y acoplamiento emocional \\
\hline & Interés empático & $\begin{array}{l}\text { Altruismo, cooperación, compasión, percepciones de } \\
\text { confianza y dolor al rechazo. }\end{array}$ \\
\hline \multirow{4}{*}{$\begin{array}{l}\text { Atribución } \\
\text { Intencional y } \\
\text { Mental }\end{array}$} & Discriminación implícita & Auto-reconocimiento y discriminación de otros \\
\hline & $\begin{array}{l}\text { Corporización de intenciones } \\
\text { (simular las acciones ajenas) }\end{array}$ & $\begin{array}{l}\text { Toma de perspectiva implícita, atribución intenciones } \\
\text { implícitas }\end{array}$ \\
\hline & $\begin{array}{l}\text { Atribución de Intenciones } \\
\text { previas }\end{array}$ & $\begin{array}{l}\text { Uso de conceptos intencionales, uso de convenciones } \\
\text { sociales }\end{array}$ \\
\hline & Atribuciones mentales & $\begin{array}{l}\text { Autoconocimiento, mentalización, falsa creencias de } \\
\text { primer orden, memoria de trabajo social }\end{array}$ \\
\hline \multirow{2}{*}{ Ejecutivos } & Inhibición afectiva & Control explícito de tendencias emocionales \\
\hline & Control cognitivo & Razonamiento social y moral, metacognición \\
\hline
\end{tabular}

Fuente: elaboración propia

\section{Sistemas de Percepción-Acción}

Esta categoría agrupa dos sistemas, el primero se compone de los procesos implicados en construcción de imágenes perceptuales a partir de las señales sociales y el segundo hace alusión a los de mecanismos que permiten la resonancia oscilatoria entre las señales sociales percibidas y los despliegues sociales ejecutados.

\section{Sistema de Mapeo Somático}

Dadas las limitaciones de espacio, el escrito se limitará al sistema visual como un ejemplo de la organización neurofuncional del mapeo somático de los estímulos sociales, no obstante, en algunas especies sociales son más relevantes los mapas auditivos, olfativos y táctiles. En primates el sistema visual es el principal dispositivo de mapeo de señales sociales y está compuesto por una variedad de regiones corticales y subcorticales involucradas en crear imágenes significativas sobre los demás.
Percepción de rostros: la percepción de los rostros permite la identificación de las personas en términos de raza, género y cercanía social, además, facilita la detección de señales afectivas y disposiciones mentales ajenas (Haxby \& Gobbini, 2011), lo cual se convierte en una habilidad importante para la supervivencia (Bachevalier \& Meunier, 2005). La percepción facial implica dos capacidades: la identificación del rostro y el reconocimiento de las expresiones faciales (Calder \& Young, 2005), Haxby y Gobbini (2011) proponen un sistema central para el análisis visual de las caras, el cual estaría compuesto por células del área occipital para caras (OFA ${ }^{2}$ ), el área fusiforme para caras $\left(\right.$ FFA $^{3}$ ) y el surco temporal superior posterior (STSp) (Figura 1). Este circuito se ha reportado en estudios de registro intracraneal en primates no humanos (Adolph, 2001), en pacientes con lesiones cerebrales y a través de imágenes funcionales del cerebro (Lieberman, 2010; Olivares \& Iglesias, 2000). La identificación de rostros se basaría en un sistema encargado de analizar rasgos invariantes, el cual depende de la actividad de OFA y FFA, mientras que el reconocimiento de expresiones estaría soportado por un sistema que codifica cambios en la configuración facial, vinculado con la actividad en el STSp (Haxby \& Gobbini, 2011). No obstante, Rhodes y colaboradores (2015) han insistido en que el procesamiento de la identidad y la expresión harían parte de un único sistema general con importantes variaciones individuales en el análisis de rasgos específicos, lo cual explicaría los cambios y la especialización en el reconocimiento facial a través del desarrollo (Wiese et al., 2013). 


\section{Figura 1}

Redes neurales que constituyen los sistemas de percepción-acción

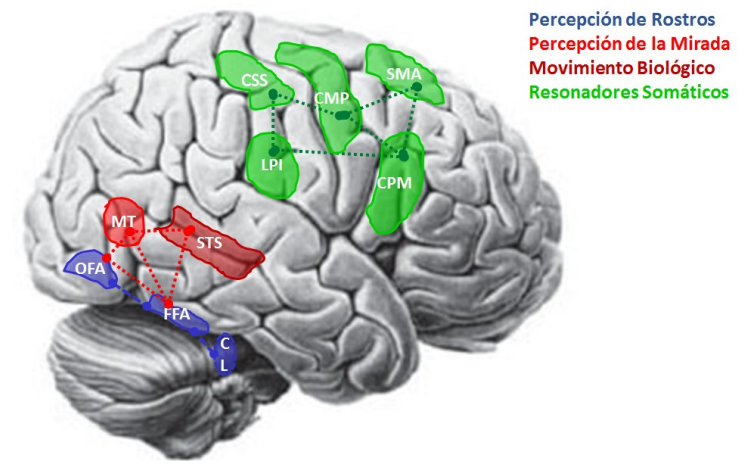

Percepción de rostros (azul), percepción de la mirada y movimiento biológico (rojo) y resonadores somáticos (verde). Las líneas punteadas indican posibles conexiones entre los componentes de los sistemas. Área fusiforme para caras (FFA), área occipital para caras (OFA), surco temporal superior (STS), área temporal medial (MT), Corteza somatosensorial ventral (CSS), Corteza motora primaria (CMP), área motora suplementaria (SMA), colículos (CL), lóbulo parietal inferior (LPI) y corteza premotora (CPM)

Fuente: elaboración propia

Además de los circuitos nucleares, se ha propuesto la participación de áreas límbicas y frontoparietales, no obstante, el reclutamiento de estas áreas depende en buena medida de la tarea empleada y podría reflejar la participación de sistemas afectivos, de atribución mental y ejecutivos (Haxby \& Gobbini, 2011; Todorov et al., 2013). Existen evidencias que indican que la neurodinámica del procesamiento facial ocurre en tres momentos: 1) una actividad positiva occipital temprana, aproximadamente a los $120 \mathrm{~ms}$ (P120), asociada con la detección visual del rostro; 2) una depleción negativa, cerca de los $170 \mathrm{~ms}$ (N170), proveniente de la corteza occipito-temporal, relacionada con la discriminación de los rostros desde otros objetos y su percepción como una Gestalt; 3) una actividad tardía vinculada con la identificación de los rostros y la asignación de un significado mnémico y afectivo (N250r y N400) (Olivares et al., 2012; Righi \& Nelson, 2012).
La capacidad de identificar rostros se desarrolla durante los primeros meses postnatales, incluso neonatos prefieren mirar objetos similares a caras (Johnson, 2005), rasgo posiblemente relacionado con procesos mesencefálicos. Durante el primer año ocurre una especialización cortical gradual, de tal forma que hacia los dos meses hay actividad metabólica en una red difusa comprendida por el giro temporal superior e inferior, regiones occipitales, parietales y frontales inferiores, lo que permite a los infantes discriminar rostros por su familiaridad, género y raza (Righi \& Nelson, 2012). Progresivamente la red se va restringiendo para proporcionar un procesamiento más preciso, que coincide con la actividad eléctrica más estable occipital y temporal (N290) (Grossmann \& Johnson, 2007).

La prosopoagnosia es la principal alteración en la percepción de rostros, se puede presentar de forma adquirida o por un desorden del neurodesarrollo, en la variante adquirida existe una seria limitación en el reconocimiento de rostros familiares (Righi \& Nelson, 2012; Susilo \& Duchaine, 2013). En niños con prosopoagnosia adquirida, los problemas incluyen limitaciones en la percepción facial y no-facial, que suelen estar asociadas a desordenes en la migración celular debidos a variaciones alélicas autosómicas dominantes (Susilo \& Duchaine, 2013).

Seguimiento de la mirada: este es un acto automático e incontenible esencial para la comunicación, que proporciona información sobre lo que los demás están atendiendo y desean hacer (Baron-Cohen, 1995), las personas que fallan en seguir la mirada son evaluados como poco fiables y deshonestos (Frith \& Frith, 2012). Otros animales como cuervos, pollos, perros, simios y ciertos reptiles pueden reconocer cuando se les mira de forma directa al detectar los pequeños cambios en los componentes de los ojos (Stone, 2007; Zuberbuhler, 2008). La mirada es procesada por una red cerebral distribuida que se traslapa con la de la percepción facial y del movimiento (Figura 1) (STS, FFA y área temporal medial) (Johnson \& Farroni, 2003; Nummenmaa \& compañeros, 2008). Carlin y 
Calder (2013) resaltan la participación del STPa, la corteza parietal lateral y la corteza prefrontal medial (CPFM), donde la STPa llevaría a cabo el análisis perceptual para determinar qué tipo de objetos está mirando una persona y la STSp estará más asociado con la percepción del movimiento biológico y la asignación de intencionalidad (Hein \& Knight, 2008; Stone, 2007).

Esta habilidad se desarrolla de forma muy temprana, neonatos son sensibles al contacto visual con miradas directas o desviadas y muestran preferencia por caras con ojos abiertos. Alrededor de los 4 meses ya son capaces de seguir los cambios en la dirección de las miradas y guiar su atención basados en la mirada ajena. Durante el segundo año adquieren la habilidad de monitorear activamente las miradas, es decir, que las pueden usar como fuente de información para guiar su aprendizaje e interacción social (Grossmann \& Johnson, 2007). El sistema de seguimiento de miradas rápidamente se integra a un sistema de resonancia motora, lo cual permite ir construyendo un conocimiento implícito de las secuencias de acciones apropiadas para los contextos sociales (León, 2013). Durante el desarrollo debe ocurrir una especialización del STS, en adultos ésta estructura presenta una amplia actividad eléctrica y metabólica ante la presentación de miradas, no obstante, en infantes la actividad eléctrica parece provenir en conjunto del STS y FFA. En bebés se han observado cambios en la amplitud del potencial eléctrico N290 tanto para dirección de la mirada como la posición de la cara, mientras que en adultos este patrón se mantiene solo para la posición de la cara, esto ha llevado a pensar que la percepción facial y la mirada comparten un sistema común durante la infancia temprana, el cual se especializa en el procesamiento de caras durante la niñez intermedia (Grossmann \& Johnson, 2007).

Alteraciones en el procesamiento de la mirada han sido reportadas en el trastorno del espectro autista (TEA) (Davies et al., 2011; Senju \& Johnson, 2008), trastorno de ansiedad social (Schulzeetal., 2013) y esquizofrenia (Hooker \& Park, 2005). Davies y colaboradores (2011) reportaron que niños TEA muestran una actividad metabólica diferente en la corteza prefrontal ventromedial (CPFvm) para miradas desviadas y directas, Auyeung y compañeros (2015) analizan la conectividad aberrante en las personas con TEA quienes presentan menor especialización hemisférica y reducida coherencia fronto-temporo-pariental la cual puede estar asociada a alteraciones en la comunicación oxitoninérgica.

Percepción del movimiento biológico: los humanos tienen una especial habilidad para discriminar objetos vivos que se mueven, en especial se parecen cuerpos humanos, (Johansson, 1973), esta habilidad se desarrolla durante el primer semestre postnatal, niños de cuatro meses muestran más preferencia por figuras humanas de puntos luminosos sin inversiones (Kuhlmeier et al. 2010, Voos et al., 2012), lo que activa una red frontotemporal (Lloyd-Fox et al., 2011), con una actividad eléctrica cerebral específica (Voos et al., 2012) y lateralizada hacia el hemisferio derecho (Grossmann \& Johnson, 2007). En adultos, parecen haber dos rutas de procesamiento: una ventral y otra dorsal (Vaina et al, 2001). La ruta ventral estaría encargada del reconocimiento de objetos socialmente significativos como las caras y los cuerpos. La ruta dorsal estaría compuesta por una red que implica la corteza intraparietal y el área temporal medial, las cuales estarían involucradas con la percepción del movimiento no-biológico, estas rutas se proyectan convergentemente sobre el STSp, la cual es esencial para el reconocimiento del movimiento biológico (Grossman et al., 2000). El STSp también está involucrado en el seguimiento de los ojos, la boca y las manos, la interpretación de la mirada y la inferencia de intenciones ajenas, por ello, para Heberlein y Adolph (2005) el STSp haría parte de un sistema de atribución automática de intenciones.

\section{Sistema de Resonadores Somáticos.}

La estrecha relación temporal entre la actividad de los sistemas perceptuales y los sistemas 
neuromotores permite un rápido acoplamiento entre los sujetos que participan en las interacciones, el cual es fundamental para el desarrollo social y el aprendizaje vicario, ya permite la incorporación de acciones socialmente relevantes. La capacidad de imitar acciones ajenas ha sido definida como "reflexión"4 o 4 resonancia social (Frith y Frith, 2012), el concepto de resonancia enfatiza la enacción y corporización durante la interacción social, ya que sucede una participación sincrónica entre agentes que componen un sistema social complejo. En este proceso parece tener especial relevancia el sistema de neuronas espejo (SNE) (Gallese et al., 1996; Ramachandran, 2010; Rizzolatti y Arbib, 1998). El SNE se ha concebido como el sustrato de la simulación, que para algunos es la base de la comprensión de los estados mentales ajenos (Iacoboni, 2009; Oberman y Ramachandran, 2006) y sería el mecanismo neural que permite la convergencia entre percepción social, preparación motora y sincronización espontánea entre individuos (Iacoboni \& Dapretto, 2006).

El SNE es un conjunto de células nerviosas ubicadas en la corteza premotora (Rizzolatti y Craighero, 2004) y parietal (Iacoboni, 2005; Iacoboni, 2009) de los simios, que presentan actividad eléctrica robusta ante la ejecución de una acción compleja o ante la percepción de acciones con objetivos similares (Fogassi \& Gallese, 2002). La respuesta eléctrica de estas células parece mantenerse aun cuando solo se brindan claves contextuales, lo que ha llevado a plantear que el SNE permite abstraer los objetivos de las acciones aprendidas (Iacoboni \& Dapretto, 2006; Umiltà Carlo, 2007). Dentro de los pocos estudios que han encontrado actividad eléctrica en espejo está el de Mukamel y compañeros (2010) quienes registraron una respuesta eléctrica similar en neuronas del área motora suplementaria y del lóbulo temporal medial ante la observación y ejecución de sonrisas y movimientos manuales. La mayor parte de las evidencias sobre un SNE humano son indirectas (Cook et al., 2014), de ellas se ha inferido que pueden existir diferentes sistemas que se comportan como resonadores neuromotores. Las principales zonas que harían parte del SNE somático son: la corteza premotora (PMC), las áreas parietales inferiores (Fadiga et al., 2002; Möhring et al., 2014; Rizzolatti y Craighero, 2004), la corteza motora suplementaria (SMA), la corteza motora primaria, corteza somatosensorial primaria y secundaria, y el cerebelo (Destro \& Rizzolatti, 2008) (Figura 1). Áreas como la ínsula anterior, la corteza cingulada anterior, la amígdala y el área parahipocampal también han recibido el trato de SNE, pero estarían más acopladas a los sistemas afectivos y a la capacidad de resonancia del sistema motor neurovegetativo, ${ }^{5}$ fundamental para contagiarse emocionalmente (Tylén et al., 2012). Con respecto a la actividad neurofisiológica, Möhring y compañeros (2014) reportan un PRE (N170) asociado con la respuesta en espejo al movimiento de los labios, con una posible localización en el LPI. Adicionalmente, la supresión del ritmo mu ha sido planteada como uno de los posibles indicadores de actividad en espejo registrada en tareas de imitación (Coll et al, 2014; Iacoboni \& Dapretto, 2006).

Se ha propuesto que el SNE es el resultado de un aprendizaje Hebbiano durante los primeros meses postnatales, por lo cual no tendría un origen innato y universal como se ha propuesto. Es probable que el SNE frontal y parietal se organice durante los tres primeros años de vida (Nyström et al., 2011) perfeccionando las habilidades de imitación y sincronía social. Se ha reportado que niños de ocho meses pueden suprimir el ritmo $m u$ durante la observación de movimientos cotidianos (Berchicci et al., 2011; Nyström et al., 2011), mientras que niños de tres años muestran una clara supresión de ondas $m u$ en tareas de intercambio social y observación de acciones sociales (Liao et al., 2015), sin embargo, no es claro si este cambio fisiológico tiene el mismo significado en niños y adultos. En conjunto estas evidencias indicarían que el funcionamiento en espejo de diferentes grupos celulares no es un antecedente sino una consecuencia de los acoples a múltiples 
niveles que ocurren durante la interacción social sincrónica (Di Paolo \& De Jaegher, 2012).

\section{Sistemas Afectivos}

Los sistemas afectivos son un grupo de mecanismos que participan en la asignación de valor biológico a la acción socialmente contextuada (León, 2012), en este modelo se contemplan tres tipos de sistemas afectivos estrechamente relacionados: mapas viscerales, resonadores afectivos y generadores de interés empático.

\section{Sistemas de Mapas Viscerales}

Son los sistemas afectivos primarios propuestos por Panksepp (1998, 2012), estos sistemas modulan la actividad endocrina y neurovegetativa en forma de mapas viscerales, los cuales se comportan como atractores neurodinámicos, de ellos emergen tanto los aspectos fenoménicos como los comportamentales de las emociones básicas. Panksepp ha propuesto siete sistemas básicos que emergerían en el cerebro-cuerpo mamífero: la búsqueda, el deseo sexual, el juego, el cuidado del otro, la angustia por separación, el temor y la ira, los cuales se constituyen sobre asambleas neurales que reúnen el sistema neurovegetativo y los núcleos del tallo cerebral como el parabranquial, del tracto solitario, el locus ceruleus, la sustancia gris periacueductal, el área tegmental ventral, el hipotálamo y la hipófisis (Para mayor información revisar, Panksepp 1998, 2012)

\section{Sistema de Resonadores Afectivos}

Este sistema se propone como un conjunto de mecanismos que median el acople entre la discriminación de expresiones emocionales, su corporización y modulación emocional automática. El modelo de simulación ha sido el de mayor acogida para la explicación de la percepción de las emociones (Adolphs, 2002;
Heberlein \& Adolphs, 2007), en este modelo, la percepción de las emociones está soportada sobre mecanismos similares a los implicados en su experiencia, lo que permite un conocimiento directo de la experiencia ajena, esta hipótesis es apoyada por estudios de registro intracraneal, neuroimagen y lesión (Heberlein \& Atkinson, 2009). Por ejemplo, Neal y Chartrand (2011) observaron que las personas con reducción en la actividad muscular facial por lesión, tratamiento con Botox o por bloqueo transitorio, tenían una menor precisión en el reconocimiento de emociones.

El reconocimiento de emociones se desarrolla principalmente en la infancia y niñez, no obstante, la precisión en la decodificación de las emociones continúa cambiando durante la pubertad en formas dependientes del género (Lawrance et al., 2015). Durante los primeros meses de vida parece existir patrones estereotipados de expresión que coinciden con las categorías emocionales adultas (Cole \& Moore, 2014), pero no es claro si estos patrones de expresión se acompañan de los cambios fisiológicos y fenoménicos que caracterizan las emociones adultas. Es probable que antes del primer semestre de vida la discriminación de expresiones faciales no sea precisa y no logre generar respuestas psicológicas distintivas (Voos et al., 2012). Evidencias comportamentales y electrofisiológicas señalan que alrededor de los siete meses los infantes comienzan a discriminar de forma consistente expresiones faciales de ira, temor y alegría (Izard et al., 2010), sin embargo, no hay evidencias si esta discriminación se mantiene para estímulos auditivos (Grossmann \& Johnson, 2007), al parecer, tanto en adultos como en infantes la discriminación auditiva es bastante limitada y solo permite distinguir entre valencias positivas y negativas (Adolphs, 2002; Heberlein \& Adolphs, 2007).

Dentro de las áreas que más se han vinculado con la percepción de emociones y que servirían como resonadores afectivos se enlistan: corteza occipitotemporal inferior, colículos, amígdala, corteza orbitofrontal (COF), ganglios basales, ínsula, corteza cingulada anterior y corteza parietal derecha (Adolph, 2002; Heberlein \& 
Adolphs, 2007; Heberlein \& Atkinson, 2009; Fusar-Poli et al., 2009). La Amígdala parece participar activamente en la discriminación de señales de amenaza, en especial rostros que expresan temor e ira, no obstante, su respuesta ante otras expresiones faciales aversivas como desagrado y tristeza aún es controversial (Adolph, 2008; Tamieto \& Gelder, 2010). Los núcleos amigdalinos parecen estar más involucrados en el aprendizaje y codificación de la intensidad de los estímulos con alta prominencia que en la asignación de un valor afectivo específico (Heberlein \& Adolphs, 2007; Bonet et al., 2015). Gelder (2006) propone dos rutas que activan la amígdala, una subcortical que parte de los colículos superiores y el núcleo pulvinar, y una cortical que proviene desde la corteza occipital, la primera participa en una detección automática de la prominencia de los estímulos, mientras que la segunda participa en un reconocimiento más lento y explícito (Gelder, 2006). La corteza insular se ha asociado con la percepción de señales viscerales e interoceptivas que sirven como retroalimentación sobre la homeostasis corporal durante las interacciones. En humanos, estudios electrofisiológicos y de neuroimagen han asociado la porción anterior insular con la percepción de sabores y olores desagradables y la porción posterior con el procesamiento de estímulos agradables (Wicker et al., 2003). Además, de la participación de la ínsula en la experiencia y reconocimiento del asco, se ha reportado que los ganglios basales y algunos núcleos amigdalinos participarían en el reconocimiento de señales desagradables condicionadas (Heberlein \& Adolphs, 2007). Estudios de lesión, neuroimagen y estimulación magnética transcraneal han coincidido en que la corteza somatosensorial derecha (CSS) participa en la percepción de emociones, las evidencias son más fuertes para emociones como temor y asco y menos consistentes para emociones positivas (Heberlein \& Atkinson, 2009), de acuerdo con Adolphs (2002) la CSS genera una imagen corporal de la emoción percibida. La corteza orbitofrontal (COF) derecha se ha asociado con el procesamiento de caras de ira más que de alegría o tristeza, daños en la COF derecha pueden conllevar a una alteración en la percepción emocional facial y auditiva, pero, parece que la COF tiene una actividad mayor cuando la tarea requiere un procesamiento explícito (Adolphs, 2002).

\section{Figura 2}

Redes neurales que componen los sistemas afectivos

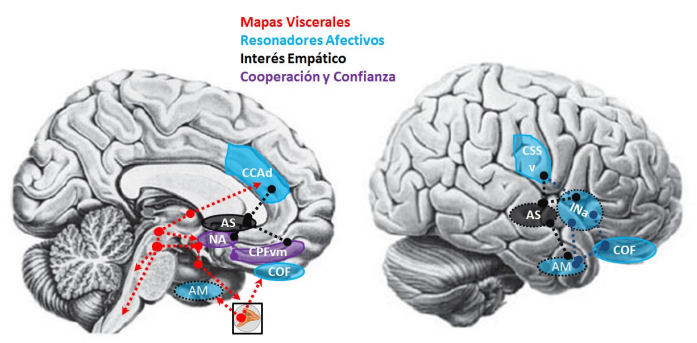

Los mapas viscerales (rojo) se componen de núcleos del tallo cerebral, hipotalámicos, mescencefálicos, hipofisarios, vías sanguíneas de comunicación hormonal y el NA. Sistema de resonadores afectivos (azul). El sistema de interés empático (negro) y las conexiones que facilitan la cooperación y percepción de honestidad (morado). Amígdala (AM), ínsula (IN), Corteza somatosensorial ventral (CSSv), Corteza orbitofrontal (COF), Núcleo Acumbens (NA) y Área Septal (AS) Fuente: elaboración propia

\section{Sistema de Interés Empático}

La empatía es una capacidad compleja que se ha ido construyendo a través de la historia evolutiva y cultural de la humanidad (Nelson, 2013), en ella convergen mecanismos afectivos, tendencias sociales, formas de pensamiento y esquemas culturales (Decety, 2007, 2015). De acuerdo con Decety y Cowell (2014), existen al menos cinco procesos que contribuyen a las respuestas empáticas: 1) contagio emocional; 2) autoconsciencia; 3) motivación empática; 4) toma de perspectiva ajena; y 5) procesos regulatorios. En este apartado se hará un énfasis sobre el contagio emocional y el interés empático; la autoconsciencia y toma de perspectiva se amplían en la categoría de atribución mental y los procesos regulatorios se abordan junto con los sistemas ejecutivos.

| Universitas Psychologica | V. I5 | No.5 | 2016 | 
La mayoría de estudios de neuroimagen funcional de la empatía se han centrado sobre el contagio emocional durante situaciones de observación y experiencia emocional, por ejemplo: cuando las personas observan vídeos de otros que son tocados o reciben estímulos táctiles activan de forma similar la CSS secundaria (Keysers et al., 2004); observar y experimentar dolor consistentemente activa la CCA (Engen \& Singer, 2013; Singer et al., 2004 y 2006); y la percepción o empatía de estímulos que causan asco conllevan a una actividad mayor de la ínsula anterior (Jabbi, Swart \& Keysers, 2007). Resultados similares se han observado en animales no humanos y en bebés de pocas semanas de nacimiento (Bischof, 1991), lo cual ha llevado a plantear que el contagio emocional debe tener un desarrollo temprano ontogenética y filogenéticamente (Hatfield \& Rapson, 2000).

La motivación empática se refiere a la urgencia e interés por mantener el bienestar de los demás (Decety \& Cowell, 2014; Morelli et al., 2012), para Lieberman (2013) este es el aspecto central de la empatía y uno de los principales en la naturaleza social humana. El componente neural central para la motivación empática es el área septal (figura 2), la cual recibe importantes aferencias desde los sistemas de recompensas, cuidado de otros, angustia a la separación, resonancia afectiva y la CPFdm, en su conjunto conforman un sistema que "permite que la respuesta afectiva sea convertida en motivación para ayudar a los demás" (Lieberman, 2013, p. 160), lo que es relevante para promover las conductas prosociales y de cuidado materno (Fleischer \& Slotnick, 1978; Moll et al., 2010). Cuando algunas personas interactúan bajo la tendencia apremiante de protegerse mutuamente emerge la cooperación, como un atributo de los sistemas sociales complejos, esto pudo ser decisivo en la supervivencia y desenvolvimiento evolutivo de las especies sociales y es un fundamento esencial para la moralidad humana (Tomasello \& Vaish, 2013).

Con respecto a la cooperación, se ha documentado que las personas suelen ser más cooperativas y altruistas si se perciben como siendo observadas (efecto de audiencia), este efecto también ha sido reportado en chimpancés (Jaeggi et al., 2010), ratas (Segura \& Gutierrez, 2006) y peces (Bshary \& Grutter, 2006). Este tipo de experimentos, muestra un alto nivel de automaticidad en la cooperación sin requerir un mecanismo racional (Jaeggi et al., 2010). Se ha visto que el sistema de recompensa dopaminérgico se activa intensamente cuando hay cooperación recíproca (Rilling y cols., 2004) y cuando se evalúan como confiables los comportamientos ajenos (Tabibnia et al., 2008), incluso, la sola presentación de un compañero cooperativo conlleva a la activación de este sistema (Frith \& Frith, 2012), lo cual ha llevado a plantear la cooperación y la ayuda a otros como un elemento altamente reforzante (Lieberman, 2013).

La atribución de honestidad es uno de los elementos más relevantes en la modulación de las respuestas empáticas (Singer et al., 2006), la cooperación y el altruismo (Tabibnia \& Lieberman, 2007). Hay evidencias que el sistema de recompensas tiene mayor actividad cuando se perciben actos honestos (Tabibnia, Satpute \& Lieberman, 2008), mientras que circuitos del dolor y asco se activan con mayor frecuencia cuando las conductas son consideradas deshonestas o injustas (Sanfey et al., 2003; Wu et al 2015) (figura 2). Se ha reportado que el nivel social modifica la honestidad percibida, de tal forma que individuos con un mayor estatus social muestran una mayor sensibilidad hacia las conductas injusta que los de bajo estatus ( $\mathrm{Hu}$ et al., 2014), lo cual ha sido corroborado en otras especies con jerarquías sociales (Brosnan \& de Waal, 2003).

Además del refuerzo de la conexión social, la desconcexión conlleva a una sensación muy desagradables. Se ha reportado que las tareas que generan exclusión activan significativamente la CCA y los sistemas neuroendocrinos del estrés (Eisenberger \& Lieberman, 2004; Eisenberger, Gable, \& Lieberman, 2007). En su conjunto, las experiencias positivas y las negativas mantendrían una constante disposición para favorecer el bienestar y evitar el dolor de aquellos que son percibidos como similares. No obstante, pueden existir variaciones individuales 
vinculadas con polimorfismos genéticos en receptores de dopamina, opioides y oxitocina que modulan la capacidad de resonancia afectiva (Mascaro et al., 2013; Wu et al., 2012).

\section{Sistemas de Atribución Intencional y Mental}

\section{Sistemas de Discriminación Implícita de Agentes}

Este sistema comprende una red neural distribuida cuya principal función es generar una imagen de sí mismo como un agente diferenciado de otros. Ser un agente social incorpora una sensación de dominio sobre las acciones que se ejecutan (agencia) (Tsakiris et al., 2007), en 1983 Libet proporcionó evidencias que las acciones voluntarias son precedidas por un potencial de preparación, este potencial proviene de la actividad de neuronas de las áreas pre-suplementaria (PreSMA) y premotora (CPM) (Haggard, 2008) (Figura 3). La sensación de control voluntario sería generada por la comunicación reverberante entre áreas laterales como la PreSMA, CPM y el surco intraprarietal (SIP), mientras que la sensación de propiedad corporal emergería de la interacción entre zonas mediales como la corteza prefrontal medial $(\mathrm{CPFm})$, la corteza cingulada posterior (CCP) y el precuneus. Alteraciones en estas redes podrían estar implicadas en los casos de miembro fantasma donde hay hiperempatía al dolor, tacto y movimiento ajeno (Ramachandran, 2011) y de sinestesia "mirror-touch" donde las personas sienten el tacto de otros (Maister, 2013).

Con respeto al autor-reconocimiento, cerca de terminar el segundo año de vida los niños ya pueden autorreconocerse ante el espejo (Gallup, 1970; Povinelli et al., 1996). En animales nohumano se ha comprobado que muchos de los grandes primates, elefantes (Plotnik et al., 2006) e incluso delfines (DeGrazia, 2009; Reiss \& Marino, 2001) han logrado identificar su reflejo en el espejo. Investigaciones con iRMF han encontrado que verse en una fotografía incrementa la actividad en regiones como la CCP, el precuneus y la CCA (Devue et al., 2007; Platek \& Thomson, 2007). Puede haber dos procesos implicados con ver la imagen propia: un mecanismo implícito para saber que esa imagen se refiere a uno mismo y uno más explícito de elaboración de creencias acerca de sí mismo.

\section{Figura 3}

Redes neurales vinculadas los sistemas de atribución intencional y mental

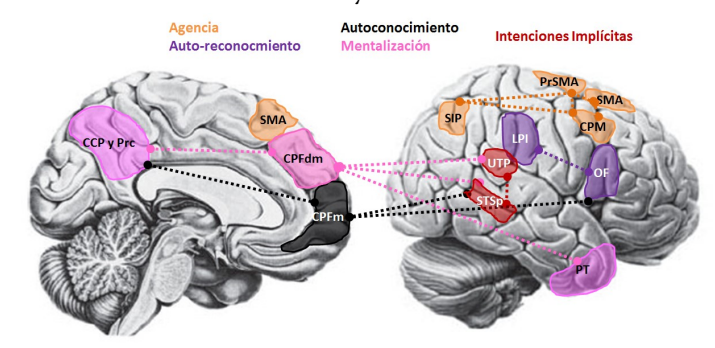

Los circuitos básicos son: agencia (naranja), autorreconocimiento (morado), autoconocimiento (negro), mentalización (rosa) y atribución implícita de intenciones (rojo). Las líneas punteadas indican posibles conexiones entre los circuitos. Lóbulo parietal inferior (LPI), precuneus (Prc), corteza cingulada posterior (CCP), polos temporales (PL), surco temporal superior posterior (STSp), unión temporoparietal (UTPJ), área motora suplementaria (SMA), área motora presuplementaria (PreSMA), corteza premotora (CPM), corteza prefrontal dorsomedial

(CPFdm), y corteza prefrontal medial (CPFm) Fuente: elaboración propia

\section{Sistema de Corporización de intenciones}

En los dos primeros años de vida se desarrolla un sistema responsable por la asignación implícita y automática de intenciones a las acciones ajenas. Se ha reportado que niños entre uno y dos años ya tienen un nivel básico de toma de perspectiva visual, ya que reconocen si un agente está mirando un objeto (Moll et al., 2006; Luo \& Baillargeon, 2007; Sodian et al., 2007). Al igual, animales no humanos parecen desarrollar niveles básicos de toma de perceptiva (Here et al., 2001), Emery (2009) menciona que animales sociales como delfines, ballenas asesinas, lobos, perros salvajes, caballos, hienas, elefantes, leones, córvidos y loros, demuestran comportamientos sociales complejos que implican toma de perspectiva implícita. Por ejemplo, hay buenos indicios de que los 
perros pueden detectar estados atencionales y emocionales de los humanos y guiar así su comportamiento (Call et al., 2002). Niños de 2.5 años y orangutanes pueden formarse imágenes sobre la reputación de otras personas a través de la observación de sus conductas (Hermann y colaboradores, 2013), lo que puede significar un proceso de domesticación en humanos y otros primates (Call \& Tomasello, 2008; Emery, 2009). Esta asignación de intenciones se hace como un proceso enactivo y no como uno inferencial (Narvaez, 2012), por ejemplo, en la toma de perspectiva espacial se formaría al emular las acciones ajenas (Kessler \& Thomson, 2010).

Con respecto a las redes neurales, trabajos con neuroimágenes y electrofisiología han encontrado que la actividad del STSp y unión temporoparietal (UTP) está asociada con la asignación automática de intenciones (Figura 3) (Frith \& Frith, 2012). Por ejemplo, Decety y Cacioppo (2012) observaron una actividad temprana (170 ms) del STSp y la UTP en situaciones de daño intencional, además, se ha reportado una actividad eléctrica temprana (200) en amígdala en condiciones de daño intencional (Hesse et al., 2016). Algunas variaciones en la asignación de intenciones podrían estar relacionadas con polimorfismos del gen del transportador de serotonina (Marsh y colaboradores, 2011a) y receptor de oxitocina (Kumsta \& Heinrichs, 2013; Walter et al., 2012), lo cual se ha asociado con fallas en el pensamiento moral en personas con rasgos de psicopatía (Marsh et al., 2011b).

\section{Sistema de Atribución de Intenciones Previas}

Este sistema se refiere a la capacidad de reconocer que las acciones pueden deberse a las intenciones que las antecedieron. En humanos, la característica principal es el uso de palabras intencionales (desear, querer, sentir, etc.) que aparecen entre el tercer y cuarto año de vida, el uso de estos conceptos pude ser el resultado de la adopción implícita de convenciones sociales y no el reflejo de representaciones conceptuales sobre el mundo social. Entre el tercer y quinto año hay un importante desarrollo del lenguaje sobre emociones y estados mentales, lo que implica al menos tres cambios: 1) incorporación de conceptos mentales, incluyendo sus significados y usos; 2) apropiación de roles y participación en escenarios sociales prototípicos; y 3) reclutamiento de regiones corticales y subcorticales que facilitan la aplicación del conocimiento léxico, semántico y social en la participación en interacciones cotidianas. Las redes que compondrían este sistema son el área parahipocampal, giro temporal superior y corteza prefrontal medial (CPFm).

\section{Sistema de Atribuciones Mentales Explícitas}

Desde su aparición en 1978 (Dennett, 1978; Premack \& Woodruff, 1978) el concepto de teoría de la mente (TdM) ha recibido una importante atención en psicología y neurociencia cognitiva, la TdM se refiere a la capacidad de ciertos animales de inferir, atribuir o comprender estados mentales ajenos (Call \& Tomasello, 2008; Benavides \& Moreno, 2011), no obstante, hay diferentes formas y niveles de obtener y usar información sobre los estados afectivos, motivacionales y creencias de los demás (Tirapu et al., 2007). Las dos aproximaciones clásicas a la TdM son: la Teoría-Teoría (TT) que se basa en los procesos de inferencia por medio de mecanismos racionales (Carruthers \& Smith, 1996; Gopnik \& Wellman, 1992); y la Teoría de la Simulación (TS) que propone que el conocimiento sobre la mente ajena se logra a través de la activación de mecanismos similares a los de la mente propia. No obstante, muchos autores prefieren no usar el término TdM dado su fuerte sesgo hacia la postura TT, en su lugar prefieren usar conceptos como el de mentalización (Frith \& Frith, 2013), éste se refiere a los procesos por medio de los que un individuo, de forma implícita y explícita, atribuye estados intencionales (deseos, necesidades, sentimientos, creencias y razones) a sí mismo y a otros (Choi-Kain y Gunderson, 2008; Fonagy y cols., 2002; Frith y Frith, 2012). Las diferentes formas de mentalización 
reportadas pueden ser agrupadas en tres niveles que se integran en un orden jerárquico: inferencia perceptual, inferencia intencional e inferencia mental (Emery \& Clayton, 2009; León, 2013), los cuales se esquematizan en la figura 4 , en la cual se muestran los tres niveles inferenciales, cinco mecanismos de mentalización con las edades aproximadas de adquisición y las posibles habilidades que dependen de estos mecanismos.

El nivel de inferencia perceptual se refiere al tipo de procesos abordados en los sistemas de percepción-acción, afectivos y de corporización de intenciones; es un conocimiento implícito, práctico y corporal de las consecuencias inmediatas que siguen a las acciones sociales típicas. Las formas más rudimentarias de este nivel solo permiten asociar contingencias con acciones sociales y se alcanza durante el primer año. Luego los niños entre el primer y segundo año logran atribuir objetivos a las acciones propias y ajenas al realizarlas o simularlas (intención en la acción), no obstante, esta habilidad se reduce a las intenciones que son visibles en las acciones, lo cual puede ser una condición sine qua non para la aparición de las formas explicitas de mentalización. La inferencia intencional se remite a los procesos abordados en el sistema de intenciones previas, se remite a la capacidad de interpretar la conducta propia y ajena como precedida por intenciones, esto es lo que Emery y Claton (2009) definen TdM motivacional.

\section{Figura 4}

Esquema sobre niveles de las habilidades relacionadas con la mentalización

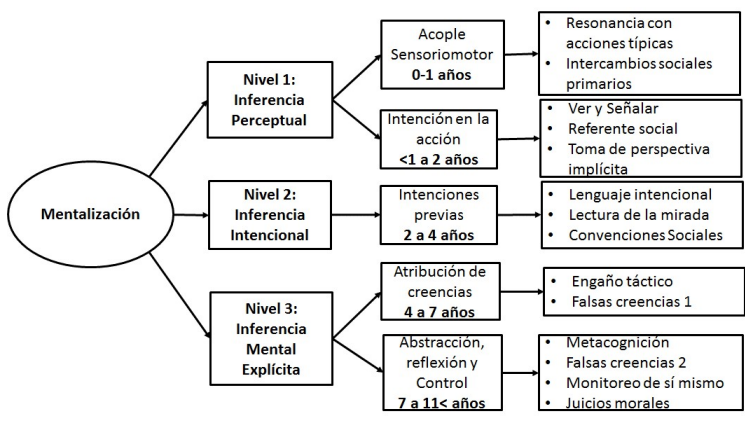

Cada nivel es segregado en habilidades específicas y cada una de ellas es vinculada con las tareas que se suelen emplear para su evaluación Fuente: elaboración propia

La inferencia mental explícita o mentalización propiamente dicha (TdM informacional en Emery, 2009), alude a la capacidad de comprender y explicar el comportamiento de los otros recurriendo a estados psicológicos, esta toma de perspectiva explícita ha sido extensamente indagada a través de tareas falsa creencia de primer orden (Baron-Cohen, Leslie \& Frith, 1985; Leslie \& Frith, 1988; Milligan et al., 2007; Wimmer \& Perner, 1983), realización y detección del engaño (Engen \& Singer 2012), generación de estados mentales en otros, y uso de doble sentido e ironías (Delgado \& Benavides, 2010; Tirapu et al., 2007), en todas estas tareas los niños mejoran su desempeño entre los cuatro y siete años (Frith \& Frith, 2003). Un grado más complejo de inferencia mental explícita requiere que las personas puedan elaborar juicios basados en procesos metacognitivos, reflexivos, de abstracción y alto uso de memoria de trabajo (Frith y Frith, 2012) y se desarrollaría de forma importante en la niñez intermedia, estos modos de funcionamiento serán abordados en el apartado de sistemas ejecutivos. Alteraciones en el desarrollo de los mecanismos que permiten la mentalización en cada uno de los anteriores niveles pueden comprometer seriamente el funcionamiento social, la comunicación con los demás, y la noción de sí mismo, fallas que suelen incluirse dentro del espectro autista 
(Baron-Cohen, Leslie \& Frith, 1985; Oberman y Ramachandran, 2007).

De acuerdo con Lieberman (2010 y 2013), durante la realización de tareas de atribución mental se suele hallar una mayor actividad de la CPFdm, los polos temprorales (PT), la UTP, el precuneus y la CCP, de forma similar estas estructuras coinciden con la red por defecto $(\mathrm{DMN})^{6}$, esta similitud ha llevado a pensar que la DMN es un sistema que funciona como una memoria de trabajo social, que se desarrolla en la infancia temprana y permite pensar deliberadamente en los otros (Lieberman, 2012a). La forma como participan estas áreas en las diferentes situaciones de mentalización es compleja y suele reflejar dinámicas temporales que conllevan a la heterogeneidad en los estudios de imágenes y actividad eléctrica sobre la TdM (Frith, 2012; León, 2013). Para Lieberman (2010) la actividad de la CPFdm sería el principal marcador de la $\mathrm{TdM}$, con una importante participación en la formación de reglas que permiten comprender cómo la mayoría experimentan y responden a diferentes situaciones. Tareas de mentalización que implican figuras animadas reclutan zonas como el PT y el STSp, lo que hace pensar que un circuito compuesto por CPFdm-PTSTSp sería relevante para la mentalización implícita (intenciones en la acción e intenciones previas). Por otro lado, actividades que inducen la mentalización de forma verbal (falsa creencia y meteduras de pata) consistentemente reclutan la UTP, pero no el PT ni el STSp, por ello es posible que la interconexión entre CPFdm-CCP-UTP (figura 4) sea una de las bases de la mentalización explicita básica (Spunt et al., 2015).

El desarrollo de un sistema de mentalización facilita la participación en escenarios e instituciones sociales normativos, lo que a su vez permite la emergencia de un pensamiento moral explícito en el que se debe juzgar la bondad o maldad de un acto, este pensamiento es soportado sobre un red neural distribuida (Young \& Dungan, 2012), que incorpora la actividad compleja y dinámica entre el septum, amígdala, STSp, CPFdm, CPFvm, UTP, CCP y precuneus (Decety \& Cacioppo, 2012; Greene,
\& Haidt, 2002; Lierberman, 2010). Fallas en la actividad de esta red puede conllevar a conductas insensibles y deshumanizantes, típicas en trastornos psicopáticos (Dadds et al., 2011; Kerr et al., 2012), conductas antisociales (Shirtcliff et al., 2009; White et al., 2013) y tendencias violentas entre géneros e intergrupales. Esta insensibilidad está asociada con un pensamiento deshumanizante, en el cual hay se reduce la actividad en el sistema de mentalización (CCP/PC, CPFm, LPI, y STS) (Jack et al., 2013). En muchos de estos casos se puede detectar una contradicción entre moralidad y empatía, ya que una fuerte respuesta empática por personas de un grupo puede llevar a respuestas agresivas y lesivas hacia personas de grupos externos (Decety et al., 2014).

El auto-conocimiento y auto-reflexión son habilidades que surgen de la integración entre el sistema de mentalización y el de elaboración de memorias biográficas, existen evidencias que asocian la actividad de la CPFm cuando las personas realizan juicios acerca de sí mismos (Heatherton, 2011; Lieberman, 2012b), además, esta zona es desproporcionadamente más grande en humanos que en otras especies de primates, lo que significaría un rasgo anatómico y funcional distintivo de la especie humana (Semendeferi et al., 2010) (Figura 4).

\section{Figura 5}

Redes neurales vinculadas los sistemas ejecutivos

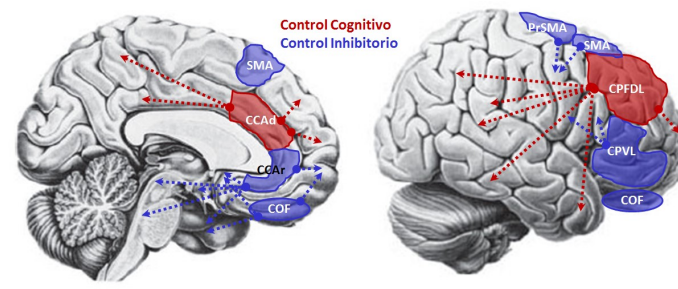

Los circuitos básicos son: control inhibitorio (azul); control cognitivo (rojo). Área motora suplementaria (SMA), área motora presuplementaria (PreSMA), corteza prefrontal ventrolateral $(\mathrm{CPFvl})$, corteza cingulada anterior rostral (CCAr), corteza cingulada anterior dorsal (CCAd), corteza orbitofrontal (COF) Fuente: elaboración propia 


\section{Sistemas Ejecutivos}

El control voluntario es de los más importantes logros del desarrollo filogenético, ontogenético y cultural humano, este control se establece a partir de la educación socioemocional que tiene lugar durante la niñez y de la integración de las regiones prefrontales en circuitos que permiten una modulación arribaabajo (top-down). Esta dinámica permite generar bucles de retroalimentación entre las demandas ambientales que generan actividad abajo arriba (botom-up) y la supervisión continua por el procesamiento descendente. Existen al menos cuatro formas de control ejecutivo: aplazamiento del refuerzo, inhibición emocional, control del pensamiento y la inhibición de impulsos motores (Lieberman, 2013). En este apartado se describirán brevemente el sistema de control cognitivo y el de control emocional.

\section{Sistema Control Cognitivo del Conocimiento Social}

Se ha documentado que la CS en los adolescentes y adultos suele estar modulada por procesos descendentes lo cual facilita la participación en instituciones sociales ampliamente complejas (Frith \& Frith, 2012), por ejemplo: en el procesamiento de claves sociales contradictorias incrementan la actividad en la corteza prefrontal dosolateral (CPFdl) y la CCAr (Zaki et al., 2010); durante la re-evaluación de prejuicios de raza hubo una amplia actividad de la CPFdl, CCAr y CPFvl (Cunninhan et al., 2004); en la racionalización en juegos económicos se observó una significativa actividad de la CPFdl (Kirk et al., 2011); el uso de un razonamiento utilitarista que requiere la solución de conflictos morales suele reclutar la CPFdl y la CCAr (Greene, 2005; Greene et al., 2004; Moll et al., 2008). Además de la función supervisora y de solución de conflictos, este sistema puede ser altamente relevante para los procesos metacognitivos, en los que se realiza una reflexión voluntaria y declarativa del conocimiento social (Frith \& Frith, 2012)

\section{Sistema de Control Emocional}

Este sistema se encarga de regular los sentimientos y comportamientos socioemocionales, para que se ajusten a las expectativas sociales. Lieberman (2010), propone que intentos explícitos de autocontrol suele activar una red cerebral que incluye la CPF lateral, CCAr, PreSMA y la CPFdm. Donde la CCA funcionaría como un sistema de detección de conflictos que indica la necesidad de autocontrol y su actividad comenzaría sobre los $300 \mathrm{~ms}$ (Angelini et al., 2016). Por otro lado, la corteza prefrontal ventrolateral CPFvl bilateral estaría más relacionada con el esfuerzo explícito de regulación emocional (Cohen J. \& Cols., 2011; Heatherton, 2011) y su actividad eléctrica sería más tardía (>450 ms) (Angelini et al., 2016). Diferentes investigaciones resaltan el papel de la CPFvl en la regulación emocional y conductual: pacientes con lesiones en la CPFvl tienden a hacer elecciones más arriesgadas en tareas de riesgo-recompensa (Bechara et al., 1994; Bechara, 2004); la CPFvl derecha está más relacionada con altas ganancias y mayor control de recompensas en juegos de cartas (Cohen et al., 2011); adultos con una mayor actividad en la CPFvl muestran menos signos de angustia ante situaciones de exclusión y rechazo social (Eisenberger \& Lieberman, 2004; Eisenberger, Gable, \& Lieberman, 2007); por último, en adolescentes maduran primero las regiones de recompensa (estriado ventral y CPFvm) que las de inhibición CPFvl y la CCAr, lo que conlleva a un incremento de las conductas de riesgo (van Leijenhorst \& Crone, 2009; van Leijenhorst et al., 2010), efecto que se ve facilitado por la presencia de pares (Blakemore \& Robbins, 2012) y la historia de rechazo social crónico durante la niñez (Peake et al., 2013).

\section{Modelo Neurodinámico de la Cognición Social}

A través del artículo se ha intentado proponer un modelo neurodinámico que permita integrar evidencias desde las neurociencias y la psicología del desarrollo de la cognición social. En este 
modelo las diferentes formas de CS emergerían a partir de la interacción compleja entre sistemas neurobiológicos y sistemas socioculturales, los cuales continuamente se retroalimentan y autoorganizan reflejando una causalidad circular. Esta dinámica podría rastrearse en escalas temporales como la filogénesis, la evolución cultural, la ontogénesis (figura 4) y situaciones cotidianas (figura 6). A continuación se hace una rápida exploración de la neurodinámica que ocurriría durante las situaciones sociales (figura 6): en ventanas temporales tempanas (5 a 20ms) (Wang et al., 2010) ocurre la construcción de imágenes sensoriales subcorticales a partir de la actividad de estructuras como los colículos superiores, inferiores y el bulbo olfatorio (Damasio, 2010), las cuales facilitan la discriminación automática de valores biológicos vitales (León, 2012); de las aferencias sensoriales subcorticales se generan imágenes afectivas primarias por parte de núcleos del tallo y límbicos que mapean y controlan la actividad visceral (figura 2), la respuesta eléctrica de estas zonas puede ocurrir entre los 30 a $150 \mathrm{~ms}$; 3) paralelamente a la generación de los mapas afectivos primaros se crean mapas perceptuales sociales (figura 1), los que podrían estar asociados a potenciales evocados que suceden $170 \mathrm{~ms}$ iniciado el estímulo social (Ibañez et al., 2012); 4) las imágenes sociales y afectivas primarias inducen la actividad de circuitos afectivos secundarios (figura 2 y 3), los cuales amplifican la respuesta afectiva primaria y facilitan la asociación entre señales perceptuales sociales y estados fisiológicos (Tamieto \& Gelder, 2010), la respuesta de estas zonas se daría entre 150 y 250ms (Adolphs, 2002, Pessoa \& Adolphs, 2010) y podría estar asociada con el contagio emocional, las motivaciones empáticas y la asignación de intenciones implícita de intenciones; 5) paralelamente a la actividad de los resonadores afectivos ocurre la de los resonadores sensoriomotores, conformando un bucle de percepción-acción que facilita la resonancia y retroalimentación entre los participantes de la interacción social (figura 1), se han reportado potenciales ERN ${ }^{7}$ (80-100ms) y FRN $^{8}(250-300 \mathrm{~ms})$ en la CCA ante situaciones desagradables (Lavin et al., 2013) y actividad eléctrica a los $170 \mathrm{~ms}$ en el LPI en tareas de imitación (Möhring et al., 2014); 6) una vez se cuentan con imágenes sociales y afectivas ocurre la generación de conocimiento social, en este nivel se dan procesos de categorización explicita en el marco de teorías mentales más consistentes (Zhen et al., 2013), en las cuales participan las redes involucradas en la mentalización y el autoconocimiento, la actividad de estas redes se daría en una tiempo cercano a los $400 \mathrm{~ms}$; 7) por ultimo tendríamos la actividad de los sistemas de control ejecutivo, responsables de la reevaluación de las imágenes afectivas y sociales creadas de forma más temprana, este control descendente se entre los 300 y 600 (Ibañez et al., 2013; Kirk et al., 2011).

\section{Figura 6}

Actividad neurodinámica de los circuitos asociados a los diferentes sistemas de la cognición social

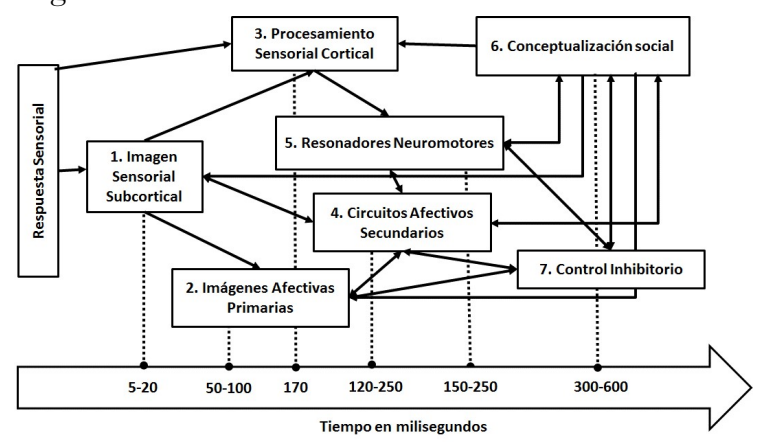

Las flechas continuas indican el sentido de la aferencia, las flechas con doble punta indican conexiones bidireccionales. Las líneas punteadas asocian rangos temporales de actividad eléctrica de cada circuito Fuente: elaboración propia

\section{Conclusiones}

La cognición social se ha convertido en uno de los temas de mayor interés dentro de la psicología cognitiva, las ciencias sociales y la neurobiología, no obstante, los modelos basados en posturas del procesamiento de información presentan diferentes dificultades conceptuales y epistemológicas. Las posturas de la cognición enactiva y de los sistemas 
dinámicos se han mostrado como una opción válida para integrar la diversidad de evidencias sobre el comportamiento social, en este sentido, el artículo intenta proporcionar un marco epistemológico que comprende el carácter sistémico, cambiante, auto-organizado, complejo, corporizado y situado del pensamiento social.

El modelo propuesto en este artículo es un paso para la construcción de una aproximación integrativa y ecológica con la cual sería posible refinar conceptual y metodológicamente la investigación sobre el comportamiento social. En un futuro próximo la neurociencia y psicología social tendrán que recurrir a diseños metodológicos en segunda persona (Schilbach et al., 2013), ya que al parecer hay profundas diferencias neurobiológicas entre observar y participar en escenarios sociales (Tylen et al., 2012), lo cual ha llevado a un serio cuestionamiento de los estudios en neurociencia cognitiva clásica, ya que gran parte de sus resultados se desprende de situaciones experimentales individuales en la que no hay genuina interacción social (Liu \& Peloswi, 2014). Una alternativa son los estudios de hiperescanéo, en los que es posible registrar en tiempo real la actividad eléctrica y metabólica encefálica de dos o más individuos que interactúan (Dumas et al., 2011), donde la actividad de los diferentes sistemas nerviosos parece acoplarse en un único sistema denominado hipercerebro (Koike et al., 2015), de tal forma que los eventos de la cognición social implicarían múltiples escalas espaciotemporales que exceden el análisis de los sistemas intraindividuales y que requerirán el empleo de modelos matemáticos que permitan analizar el comportamiento complejo y dinámico (Richardson et al., 2014).

\section{Referencias}

Adolphs R. (1999). "Social Cognition and the Human Brain." Trends in Cognitive Sciences, 3, 469-479.
Adolphs, R. (2001). The neurobiology of social cognition. Current Opinion in Neurobiology, 11, 231-239.

Adolphs, R., Gosselin, F., Buchanan, T. W., Tranel, D., Schyns, P., \& Damasio, A. R. (2005). A mechanism for impaired fear recognition after amygdala damage. Nature, $433,68-72$.

Adolphs, R. (2002). Neural systems for recognizing emotion. Current Opinion in Neurobiology, 12(2), 169-177

Adolphs, R. (2008). Fear, faces, and the human amygdala. Current Opinion in Neurobiology, 18(2):166-72

Angelini M, Calbi M, Ferrari A, SbrisciaFioretti B, Franca M, Gallese V, et al. (2016) Proactive Control Strategies for Overt and Covert Go/NoGo Tasks: An Electrical Neuroimaging Study. PLoS ONE 11(3): e0152188. doi:10.1371/ journal.pone.0152188

Auyeung B., Lombardo M., Heinrichs M., Chakrabarti B., Sule, Deakin J., Bethlehem R., Dickens L., Mooney N., Sipple J., Thiemann P., \& Baron-Cohen S. (2015). Oxytocin increases eye contact during a real-time, naturalistic social interaction in males with and without autism. Translational Psychiatry, 5, e507; doi:10.1038/tp.2014.146

Barrett L., \& Satpute A., (2013). Largescale brain networks in affective and social neuroscience: towards an integrative functional architecture of the brain. Current Opinion in Neurobiology, 23, 361372.

Bachevalier J, \& Meunier M., (2005). The neurobiology of social-emotional cognition in nonhuman primates. In: Easton A, Emery NJ, editors. The Cognitive Neuroscience of Social Behaviour. Psychology Press; London: pp. 19-57.

Baron-Cohen, S., Leslie, A., \& Frith, U. (1985). Does the autistic children have a theory of mind?. Cognition, 21, 37-46.

Beer, J. S., \& Ochsner, K. N. (2006). Social cognition: a multi level analysis. Brain 
Research 1079, 98-105. doi: 10.1016/ j.brainres.2006.01.002

Bechara, A. (2004). The role of emotion in decision-making: evidence from neurological patients with orbitofrontal damage. Brain and Cognition, 55 (1), 30-40.

Bechara, A., Damasio, H., Tranel, D., \& Anderson, S. W. (1998). Dissociation of working memory from decision making within the human prefrontal cortex. The Journal of Neuroscience, 18(1), 428-37.

Bischof, K., (1991). The Development of Empathy in Infants. In Lamb M. E. \& Keller H. Infant Development: Perspectives from German Speaking Countries. Chap. 12, pp 245-273. Hillsdale: Lawrence Erlbaum.

Berchicci, M., Zhang, T., Romero, L., Peters, A., Annett, R., et al. (2011). Development of mu rhythm in infants and preschool children. Developmental Neuroscience, 33, 130-143. doi: http://dx.doi.org/10.1159/00 0329095

Blakemore, S-J. \& Robbins, T.W. (2012). Decision-making in the adolescent brain. Nature Neuroscience 15, 1184-1191

Bonnet L., Comte A., Tatu L., Millot J.L., Moulin T., \& Medeiros de Bustos E., (2015). The role of the amygdala in the perception of positive emotions: an "intensity detector". Frontiers Behavioral in Neuroscience. 7, 9:178. doi: $10.3389 /$ fnbeh.2015.00178.

Brosnan, S. F. \& de Waal, F. B. M. (2003). Monkeys reject unequal pay. Nature 425, 297--299

Cacioppo, J. T., \& Berntson, G. G. (2002). Social neuroscience. En Cacioppo, J. T., Berntson, G. G., Adolphs, R., Carter, C. S., Davidson, R. J., McClintock, M. K., McEwen, B. S., Meaney, M. J., Schacter, D. L., Sternberg, E. M., Suomi, S. S. \& Taylor, S. E. (Eds.). Foundations in social neuroscience (pp. 3-10). Cambridge, MA: MIT Press.

Calder, A. J., \& Young, A. W. (2005). Understanding the recognition of facial identity and facial expression. Nature Reviews Neuroscience, 6, 641-651.

Call, J., Braüer, J., Kaminski, J. \& Tomasello, M. (2003). Domestic dogs (Canis familiaris) are sensitive to the attentional state of humans. Journal of Comparative Psychology, 117, 257-263.

Call J, \& Tomasello M (2008). Does the chimpanzee have a theory of mind? 30 years later. Trends in Cognitive Science, 12:187192

Carlin \& Calder (2013). The neural basis of eye gaze processing. Current Opinion in Neurobiology, 23, 450-455.

Carruthers, P., \& Smith, P. (1996). (Eds). Theories of theories of mind. Cambridge: Cambridege University Press.

Choi-Kain L., Gunderson J., (2008). Mentalization: Ontogeny, Assessment, and Application in the Treatment of Borderline Personality Disorder. The American Journal of Psychiatry, 165, 1127-1135.

Cohen, J. R., Berkman, E. T., \& Lieberman, M. D. (2011). Ventrolateral PFC as a self-control muscle and how to use it without trying. In D. T. Stuss \& R. T. Knight (Eds.), Principles of Frontal Lobe Functions (2nd ed.). Oxford: Oxford University Press.

Coll, M-P., Bird, G., Catmur, C., \& Press, C. (2014) Crossmodal repetition effects in the mu rhythm indicate tactile mirroring during action observation. Cortex, 63, 121-131.

Cunningham, W. A., Johnson, M. K., Raye, C. L., Chris Gatenby, J., Gore, J. C., \& Banaji, M. R. (2004). Separable neural components in the processing of black and white faces. Psychological Science, 15, 806-13

Dadds, M., Jambrak, J., Pasalich, D., Hawes, D., \& Brennan, J. (2011). Impaired attention to the eyes of attachment figures and the developmental origins of psychopathy. Journal of Child Psychology and Psychiatry, 52(3), 238-245.

De Jaegher H, Di Paolo E, \& Gallagher S (2010). Can social interaction constitute social cognition?. Trends in Cognitive Sciences, 14(10), 441-447. doi:10.1016/ j.tics.2010.06.009.

De Jaegher H, \& Di Paolo E (2007). Participatory Sense-Making: An enactive approach to social cognition. Phenomenology and the Cognitive Sciences, 6(4), 485-507. 
De Gelder B. (2006). Towards the neurobiology of emotional body language. Nature Reviews Neuroscience, 7(3), 242-249.

Decety, J. (2007). A social cognitive neuroscience model of human empathy. In E. Harmon-Jones and P. Winkielman (Eds.), Social Neuroscience: Integrating Biological and Psychological Explanations of Social Behavior (pp. 246-270). New York: Guilford Publications.

Decety J., (2015). The neural pathways, development and functions of empathy. Current Opinion in Behavioral Sciences, 3, 16. http://dx.doi.org/10.1016/j.cobeha.2014. 12.001

Decety J., \& Cacioppo, S., (2012). The speed of morality: a high-density electrical neuroimaging study. Journal of Neurophysiology, 108: 3068-3072, doi:10.1152/jn.00473.2012.

Decety J., \& Cowell J.M., (2014). The complex relation between morality and empathy. Trends in Cognitive Sciences, 18, 337-339.

DeGrazia (2009). "Self-Awareness in Animals," en Robert Lurz (ed.), The Philosophy of Animal Minds. (pp. 201-217), Cambridge University Press.

Dennett, D. (1978). Cognition and consciousness in non human species. Commentary. Behavioral $\mathcal{B}$ Brain Science, 4, 568-569.

Devue, C., Collette, F., Balteau, E., Degueldre, C., Luxen, A., Maquet, P. \& Brédart, S. (2007). 'Here I am: The cortical correlates of visual selfrecognition', Brain Research, 1143, 169-182.

Di Paolo, E. D., \& De Jaegher, H. D. (2012). The interactive brain hypothesis. Frontiers in Human Neuroscience, 6:163. doi: 10.3389/ fnhum.2012.00163

Dumas, G., Nadel, J., Soussignan, R., Martinerie, J., \& Garnero, L., (2010). Inter-brain synchronization during social interaction. PLoS ONE 5 (8), e12166.

Emery N., (2009). The evolution of social cognition. Chapter 5 in: The Cognitive Neuroscience of Social Behaviour, N.
Emery and A. Easton (eds.) Philadelphia: Psychology Press.

Emery N., \& Clayton N., (2009). Comparative Social Cognition. Annual Review of Psychology, 60:87-113. doi: 10.1146/ annurev.psych.60.110707.163526.

Eisenberger, N. I., \& Lieberman, M. D. (2004). Why rejection hurts: A common neural alarm system for physical pain and social pain. Trends in Cognitive Sciences, 8, 294 300.

Eisenberger, N. I., Taylor, S. E., Gable, S. L., Hilmert, C. J., \& Lieberman, M. D. (2007). Neural pathways link social support to attenuated neuroendocrine stress response. Neurolmage, $35,1601-1612$.

Eisenberger N. (2013). Social ties and health: a social neuroscience perspective. Current Opinion in Neurobiology, 23,407-413.

Ekman, P. (1994). All Emotions Are Basic. En P. Ekman \& R. Davidson, The Nature of Emotion: Fundamental Questions. Pp. 56-58. New York: Oxford University Press.

Easton, A. \& Emery, N. J. (Eds.) (2005). The cognitive neuroscience of social behavior. Hove, East Sussex, Reino Unido: Psychology Press.

Engen H., \& Singer T., (2013). Empathy circuits. Haakon G. Current Opinion in Neurobiology, 23,275-282

Fadiga, L., Craighero, L., Buccino, G., \& Rizzolatti, G. (2002). Short communication: Speech listening specifically modulates the excitability of tongue muscles: A TMS study. European Journal of Neuroscience, 15, 399-402.

Fleischer, S., \& Slotnick BM (1978). Disruption of maternal behavior in rats with lesions of the septal area. Physiology Behaviour. 21, 189-200.

Fonagy, P., Gergeley G, Jurist E, \& Target M., (2002). Affect Regulation, Mentalization, and the Development of the Self. New York, Other Press.

Frith, C., (2008) Social cognition. Philosophical Transactions of the Royal Society B, 363, 2033-2039 doi:10.1098/rstb.2008.0005. 
Frith C., \& Frith U., (2012). Mechanisms of Social Cognition. Annual Review in Psychology. 63, 287-313.

Fusar-Poli, P., Placentino, A., Carletti, F., Landi, P., Allen, P., Surguladze, S., ... \& Politi, P., (2009). Functional atlas of emotional faces processing: a voxel-based meta-analysis of 105 functional magnetic resonance imaging studies. Journal of Psychiatry Neuroscieces. 34, 418-432.

Gallagher, H. L., Jack, A. I., Roepstorff, A., \& Frith, C. D. (2002). Imaging the intentional stance in a competitive game. Neuroimage $16,814-21$

Gallup, G.G., Jr. (1970). Chimpanzees: Self Recognition. Science, 167, 86-87.

Gopnik, A., \& Wellman, H. (1992). Why the child's theory of mind really is a theory. Mind and Language, 7(1-2), 145-171.

Goldman A., \& Vignemont F., (2009) Is social cognition embodied? Trends in Cognitive Science, 13 (4). doi:10.1016/ j.tics.2009.01.007.

Grande-García (2009). Neurociencia social: El maridaje entre la psicología social y las neurociencias cognitivas. Revisión e introducción a una nueva disciplina. Anales de psicología, 25(1) 1-20.

Greene, J., \& Haidt, J. (2002). How (and where) does moral judgment work?. Trends in Cognitive Sciences, 6, 517-523.

Greene, J. D., Nystrom, L. E. , Engell, A. D., Darley, J. M., \& Cohen, J. D. (2006). The neural basis of cognitive conflict and control in moral judgement. Neuron, 44, $389-400$.

Greene J. (2005). Emotion and cognition in moral judgment: evidence from neuroimaging. In Changeux JP, Damasio AR, Singer R, Christen Y, eds. Neurobiology of human values. Berlin: Springer-Verlag; $\mathrm{p}$. 57-67.

Grossmann, T., \& Johnson, M. (2007). The development of the social brain in infancy. European Journal of Neuroscience, 25, 909-919.

Grossman, E., Donnelly, M., Price, R., Pickens, D., Morgan, V., Neighbor, G., \& Blake, R.
(2000). Brain areas involved in perception of biological motion. Journal in Cognitive Neurosciences. 12, 711-720

Haggard, P. (2008) Human volition: towards a neuroscience of will. Nature reviews: neuroscience. 9 (12), pp. 934-946 Basingstoke: Palgrave Macmillan.

Harmon-Jones, E. \& Winkielman, P. (2007). Social Neuroscience. Integrating biological and psychological explanations of social behavior. Guilford Press. New York.

Hare, B., Call, J., \& Tomasello, M. (2001). Do chimpanzees know what conspecifics know? Animal Behaviour, 61, 139-151.

Hatfield, E. \& Rapson, R. L. (2000). Emotional contagion. In Craighead W. E., \& Nemeroff C. B (Eds.). The Corsini encyclopedia of psychology and behavioral science. New York: John Wiley \& Sons, 493-495.

Haxby J. V., \& Gobbini M. I. (2011). Distributed Neural Systems for Face Perception, in The Oxford Handbook of Face Perception, Eds Calder A. J., Rhodes G., Johnson M., editors. New York, NY: Oxford University Press; 93-110.

Heatherton, T. F. 2011. Neuroscience of self and self-regulation. Annual Review in Psychology. 62: 363-90.

Heberlein, A. S., \& Adolphs, R. (2005). Functional anatomy of human social cognition. In: The Cognitive Neuroscience of Social Behaviour, N. Emery and A. Easton (eds.) Philadelphia: Psychology Press.

Heberlein AS, \& Adolphs R. (2007). Neurobiology of emotion recognition: Current evidence for shared substrates. In: Social Neuroscience: Integrating Biological and Psychological Explanations of Social Behavior, E. Harmon-Jones and P. Winkielman (eds.) New York: Guilford Press.

Hein, G., \& Knight, R.T., (2008). Superior temporal sulcus - it's my area: or is it? Journal in Cognitive Neurosciences. 20 (12), 2125-2136

Herrmann, E., Keupp, S., Hare, B., Vaish, A., \& Tomasello, M. (2013). Direct and indirect reputation formation in non-human great 
apes and human children. Journal of Comparative Psychology, 127(1), 63-75.

Hesse E., Mikulan E., Decety J., Sigman M., Garcia MC., Silva W., ... \& Ibanez A. (2016). Early detection of intentional harm in the human amygdala. Brain, 139(1), 54-61. doi: 10.1093/brain/awv336

Hu J., Cao Y., Blue F., \& Zhou X., (2014). Low social status decreases the neural salience of unfairness. Frontiers in Behavioral Neuroscience, 8, 402.

Hooker, C., \& Park, S. (2005). You must be looking at me: The nature of gaze perception in schizophrenia patients. Cognitive Neuropsychiatry, 10, 327-345.

Iacoboni M., (2009). Las neuronas espejo: Empatía, neuropolítica, autismo, imitación, o de cómo entendemos a los otros. Katz editores.

Iacoboni, M. \& Dapretto, (2006). The mirror neuron system and the consequences of its dysfunction. Nature Reviews Neuroscience. 7, 942-951.

Ibañez A., Melloni M., \& Huepe D., (2012). What event-related potentials (ERPs) bring to social neuroscience?. Social Neuroscience, 7, 632-49.

Izard, C. E., Woodburn, E. M., \& Finlon, K. J. (2010). Extending emotion science to the study of discrete emotions in infants. Emotion Review, 2, 134-136. doi: 10.1177/1754073909355003

Jabbi, M., Swart, M., \& Keysers, C. (2007). Empathy for positive and negative emotions in the gustatory cortex. Neurolmage, 34, 1744- 1753

Jack A., Dawson A., \& Norr M., (2013). Seeing human: Distinct and overlapping neural signatures associated with two forms of dehumanization. NeuroImage 79, 313-328.

Kerr, M., van Zalk, M., \& Stattin, H. (2012). Psychopathic traits moderate peer influence on adolescent delinquency. Journal of Child Psychology and Psychiatry, 53, 826-835.

Kessler, K., \& Thomson, L. A. (2010). The embodied nature of spatial perspective taking: embodied transformation versus sensorimotor interference. Cognition, 114(1), 72-88.
Keysers, C. Wicker B., Gazzola V., Anton J., Fogassi L., \& Gallese V., (2004). A Touching Sight: SII/PV Activation during the Observation and Experience of Touch. Neuron, 42, 335-346.

Kirk, U., Downar, J., \&Montague, P. R. (2011). Interoception drives increased rational decision-making in meditators playing the Ultimatum Game. Frontiers in Neuroscience, 5:49

Koike T., Tanabeb H., \& Sadato N., (2015). Hyperscanning neuroimaging technique to reveal the "two-in-one" system in social interactions. Neuroscience Research, 90, 2532.

Johnson, M. H., (2005). Subcortical face processing. Nature Reviews Neuroscience, 6, 766-774.

Johnson, M. H., \& Farroni, T. (2003). Perceiving and acting on the eyes: The development and neural basis of eye gaze perception. In O. Pascalis \& A. Slater (Eds.), The development of face processing in infancy and early childhood: Current perspectives (pp. 155-168). New York: Nova Science Publishers.

Johansson, G. (1973) Percept. Psychophys. 14, 201-211.

Kuhlmeier V. A., Troje N. F., \& Lee V., (2010). "Young infants detect the direction of biological motion in point-light displays,". Infancy, 15(1), 83-93.

Kumsta R. \& Heinrichs M., (2013). Oxytocin, stress and social behavior: neurogenetics of the human oxytocin system. Current Opinion in Neurobiology, 23:11-16

León D. (2010). El Carácter Afectivo de la Consciencia. En Roso J. \& Pérez A. El Reto de La Conciencia. Respuestas desde la psicología y la neurociencia. Editorial PSICOM Editores, Bogotá, Colombia.

León Diego A. (2012) Afectividad y Conciencia: la experiencia subjetiva de los valores biológicos. Revista Chilena de neuropsicología. 7(3) 108-114.

León Diego A (2013). Introducción a la cognición social y la neurociencia social cognitiva. Contextos en Psicología, 9, 1-12. 
León D., \& Martinez F., (2009). ¿Pueden las Neuronas Espejo Ser una Respuesta al Nacimiento de la Autoconsciencia?. Poliantea. 9, 55-69.

Leslie, A. M., \& Frith, U. (1988). Autistic children's understanding of seeing, knowing and believing. British Journal of Developmental Psychology, 6, 315-324.

Liao Y., Acar Z., Makeig S, \& Deak G., (2015). EEG imaging of toddlers during dyadic turn-taking: $\mathrm{Mu}$-rhythm modulation while producing or observing social actions. Neurolmage, 112, 52-60.

Libet, B. (1983). Time of conscious intention to act in relation to onset of cerebral activity (readinesspotential). The unconscious initiation of a freely voluntary act. Brain 106, 623-642.

Lieberman, M. D. (2007a). Social cognitive neuroscience. In R. F. Baumeister \& K. D. Vohs (Eds.), Encyclopedia of Social Psychology. Thousand Oaks, CA: Sage Press.

Lieberman, M. D. (2007b). Social cognitive neuroscience: A review of core processes. Annual Review of Psychology, 58, 259-89.

Lieberman, M. D. (2010). Social cognitive neuroscience. S. T. Fiske, D. T. Gilbert, \& G. Lindzey (Eds). Handbook of Social Psychology (5th ed.) (pp. 143-193). New York, NY: McGraw-Hill.

Lieberman M. D. (2012a). Education and the social brain. Trends in Neuroscience and Education, 1, 3-9.

Lieberman, M. D. (2012b). Self-knowledge: From philosophy to neuroscience to psychology. S. Vazire \& T. D. Wilson (Eds.) Handbook of Self-knowledge (pp. 63-76). New York: Guilford.

Lieberman, M. D. (2013). Peaks and Valleys. In Lieberman Social: why our brains are wired to connect. Ed. Crown Publishers. New York.

Liu, T., \& Pelowski, M., (2014). Clarifying the interaction types in two-person neuroscience research. Frontiers in Human Neuroscience, 8, 276.

Luo, Y., \& Baillargeon, R. (2007). Do 12.5month-old infants consider what objects others can see when interpreting their actions? Cognition, 105(3), 489-512.

Mascaro J., Rilling J., Negi L., \& Raison C., (2013). Compassion meditation enhances empathic accuracy and related neural activity. SCAN 8, 48-55.

Maister L., Banissy M., \& Tsakiris M., (2013). Mirror-touch synaesthesia changes representations of self-identity. Neuropsychologia, 51, 802-808.

Marsh, A., Crowe, S., Yu, H., Gorodetsky, E., Goldman, D., \& Blair, R. (2011a). Serotonin Transporter Genotype (5HTTLPR) Predicts Utilitarian Moral Judgments, PLoS ONE, 6 (10) DOI:10.1371/journal.pone.0025148

Marsh, A. A., Finger, E. C., Fowler, K. A., Jurkowitz, I. T., Schechter, J. C., Yu, H. H., Pine, D. S., \& Blair, R. J. R. (2011b). Reduced amygdala-orbitofrontal connectivity during moral judgments in youths with disruptive behavior disorders and psychopathic traits. Psychiatry Research: Neuroimaging, 194, 279-286.

Milligan, K., Astington, J. W., \& Dack, L. A. (2007). Language and theory of mind: Meta-analysis of the relation between language ability and false-belief understanding. Child Development, 77, 622646.

Morelli, S.A., Rameson, L.T., \& Lieberman, M.D. (2014). The neural components of empathy: predicting daily prosocial behavior. Social Cognitive and Affective Neuroscience. 9, 39-47.

Moll J., Zahn R., de Oliveira-Souza R., Bramati I.E., Krueger F., Tura B., Cavanagh A.L., \& Grafman J., (2011). Impairment of prosocial sentiments is associated with frontopolar and septal damage in frontotemporal dementia. Neuroimage. 54(2), 1735-42. doi: 10.1016/j.neuroimage.2010.08.026. Epub 2010 Aug 20.

Moll, J., De Oliveira-Souza, R., \& Zahn, R. (2008). The neural basis of moral cognition: sentiments, concepts, and values. Annals of the New York Academy of Sciences, 
1124(N/A), 161-180. [N/A]. 10.1196/ annals. 1440.005

Moll, H., \& Tomasello, M. (2006). Level I perspective-taking at 24 months of age. British Journal of Developmental Psychology, 24, 603-613.

Möhring N, Brandt E., Mohr B., Pulvermüller F., \& Neuhaus A., (2014). ERP adaptation provides direct evidence for early mirror neuron activation in the inferior parietal lobule. International Journal of Psychophysiology,. 94(1), 76-83. doi: 10.1016/j.ijpsycho.2014.07.001.

Mukamel, R., Ekstrom, A. D., Kaplan, J., Iacoboni, M. \& Fried, I. (2010). Single neuron responses in humans during execution and observation of actions. Current Biology 20(8), 750-56.

Narvaez D., (2012). Moral Neuroeducation from Early Life Through the Lifespan. Neuroethics 5, 145-157. DOI 10.1007/ s12152-011-9117-5

Nyström, P., Ljunghammar, T., Rosander, K., \& von Hofsten, C., (2011). Using mu rhythm desynchronization to measure mirror neuron activity in infants. Developmental Science, 14, 327-335.

Nummenmaa, L., Passamonti, L., Rowe, J. B., Engell, A. D., \& Calder, A. J. (2009). Connectivity analysis reveals a cortical network for eye gaze perception. Cerebral Cortex, 20, 1780-1787.

Oberman \& Ramachandran (2007). The Simulating Social Mind: The Role of the Mirror Neuron System and Simulation in the Social and Communicative Deficits of Autism Spectrum Disorders. Psychological Bulletin, 133(2), 310-327.

Olivares E. \& Iglesias J., (2000). Bases neurales de la percepción y el reconocimiento de caras. Revista de Neurología, 30(10), 946-952.

Olivares E., Saavedra C., \& Iglesias J., (2012). Potenciales evocados como marcadores neurofisiológicos de la percepción y el reconocimiento de caras. Revista Latinoamericana de Psicología, 44 (2), 27-38.
Panksepp, J. (1998). Affective Neuroscience. New York: Oxford University Press.

Peake S., Dishion T., Stormshak E., Moore W., \& Pfeifer J., (2013). Risk-taking and social exclusion in adolescence: Neural mechanisms underlying peer influences on decision-making. Neurolmage 82 (2013) 23-34.

Pelphrey K, Adolphs R, \& Morris JP (2004). Neuroanatomical substrates of social cognition dysfunction in autism. Mental retardation and developmental disabilities research reviews, 10(4), 259-71.

Platek, S. M. \& Thomson, J. W. (2007). Neural correlates of facial resemblance. En S. M. Platek, J. P. Keenan y T. K. Shackelford (Eds.), Evolutionary cognitive neuroscience (pp. 221-243). Cambridge, MA: MIT Press.

Plotnik, J. M., de Waal, F. B. M., \& Reiss, D. (2006). Self-recognition in an Asian elephant. Proceedings of the National Academy of Sciences, USA, 103.

Povinelli, D. J., Landau, K. R. \& Perilloux, H. K. (1996). Self-recognition in young children using delayed versus live feedback: evidence of a developmental asynchrony. Child Development, 67, 1540-1554.

Premack D, \& Woodruff, G. (1978). Does chimpanzee have a theory of mind? Behavioral Brain Science. 4, 9-30.

Premack, D. (1988). 'Does the chimpanzee have a theory of mind' revisited. In R. W. Byrne (Ed.), Machiavellian intelligence: Social expertise and the evolution of intellect in monkeys, apes, and humans (pp. xiv, 413). New York, NY, US: Clarendon Press/ Oxford University Press.

Ramachandran V., (2011). The Tell-Tale Brain: Unlocking the Mystery of Human Nature. William Heinemann.

Reiss, D \& Marino, L (2001). Mirror selfrecognition in the bottlenose dolphin: A case of cognitive convergence. Proceedings of the National Academy of Sciences USA, 98, 5937-5942.

Richardson, M. J., Dale, R., \& Marsh, K. (2014). "Complex dynamical systems in social and personality psychology: theory, modeling 
and analysis," in Handbook of Research Methods in Social and Personality Psychology, eds H. T. Reis and C. M. Judd (New York, NY: Cambridge University Press), 253-282

Righi, G., \& Nelson, C.A. (2012). The neural architecture and developmental course of face processing. In P. Rakic \& J. Rubenstein (Eds.), Comprehensive developmental neuroscience. San Diego, CA: Elsevier.

Rilling, J. K., Sanfey, A. G., Aronson, J. A., Nystrom, L. E., \& Cohen, J. D. (2004). The Neural Correlates of Theory of Mind within Interpersonal Interactions. Neuroimage, 22 (4), 1694-1703.

Rizzolatti, G., \& Arbib, M. A. (1998). Language within our grasp. Trends in Neurosciences, 21, 188-194.

Rizzolatti G, \& Craighero L., (2004). The mirror-neuron system. Annual Review of Neuroscience, 27, 169-192.

Russell, J. A. (2003). Core affect and the psychological construction of emotion. Psychological Review, 110, 145172.

Rhodes G., Pond S., Burton N., Kloth N., Jeffery L., Bell J., ... \& Palermo R., (2015). How distinct is the coding of face identity and expression. Cognition, 142, 123-127.

Rushworth M., Mars R., \& Sallet J., (2013). Are there specialized circuits for social cognition and are they unique to humans?. Current Opinion in Neurobiology, 23:436442.

Ruttan R., McDonnell M., \& Nordgren L., (2015). Having "Been There" Doesn't Mean I Care: When Prior Experience Reduces Compassion for Emotional Distress. Journal of Personality and Social Psychology, 108(4), 610-622.

Sanfey A.G., Rilling J., Aronson J., Nystrom L., \& Cohen J. (2003) "The Neural Basis of Economic Decision Making,". Science, 300, 1755-1758.

Schilbach L, Timmermans B, Reddy V, Costall A, Bente G, Schlicht T, \& Vogeley K. (2013). Toward a secondperson neuroscience. Behavioral and Brain
Sciences, 36(4):393-414. doi: 10.1017/ S0140525X12000660.

Segura A. \& Gutiérrez G., (2006). Cooperación en Ratas: Efectos de la Experiencia Temprana. Revista Interamericana de Psicología/Interamerican Journal of Psychology, 40(2), 241-252.

Semendeferi, K., Schleicher, A., Zilles, K., Armstrong, E., \& Van Hoesen, G. W. (2001). Evolution of The hominoid prefrontal cortex: imaging and quantitative analysis of area 10. American Journal of Physical Anthropology, 114, 224\#241.

Shirtcliff, E. A., M. J. Vitacco, A. R. Graf, A. J. Gostisha, J. L. Merz, \& C. Zahn-Waxler. 2009. "Neurobiology of empathy and callousness: Implications for the development of antisocial behavior." Behavioral Sciences and the Law, 27, 137-171.

Singer, T., Seymour, B., O' Doherty, J., Kaube, H., Dolan, R., \& Frith, C. D. (2004). Empathy for pain involves the affective but not sensory components of pain. Science, 303, 1157 - 1162 .

Singer, T., Seymour, B., O ' Doherty, J. P., Stephan, K. E., Dolan, R. J., \& Frith, C. D. (2006). Empathetic neural responses are modulated by the perceived fairness of others. Nature, 439, $466-469$.

Schulze, L., Renneberg, B., \& Lobmaier, J. S. (2013). Gaze perception in social anxiety and social anxiety disorder. Frontiers in Human Neuroscience.

Sodian, B., Thoermer, C., \& Metz, U. (2007). Now I see it but you don't: 14-montholds can represent another person's visual perspective. Developmental Science, 10, 199-204.

Spunt, R., Meyer M., \& Lieberman M., (2015). The Default Mode of Human Brain Function Primes the Intentional Stance. Journal of Cognitive Neuroscience 27, 6, $1116-1124$

Susilo, T., \& Duchaine, B., (2013). Advances in developmental prosopagnosia research. Current Opinion in Neurobiology, 23, 423429. 
Stellar J., Cohen A., Oveis C., Keltner D., (2015). Affective and Physiological Responses to the Suffering of Others: Compassion and Vagal Activity. Journal of Personality and Social Psychology, 108 (4), 572-585

Taylor, V., Daneault V., Grant J., Scavone G., Breton E., Roffe-Vidal S., ... \& Beauregard M., (2013). Impact of meditation training on the default mode network during a restful state. SCAN 8, 4-14.

Tabibnia G, Satpute AB, Lieberman MD. (2008). The sunny side of fairness. Psychological Science, 19:339.

Tabibnia, G. \& Lieberman, M. D. (2007). Fairness and cooperation are rewarding: Evidence from social cognitive neuroscience. Annals of the New York Academy of Sciences, 1118, 90-101.

Tabibnia, G., Satpute A. B., \& Lieberman, M. D. (2008) The sunny side of fairness: preference for fairness activates reward circuitry (and disregarding unfairness activates self-control circuitry). Psychological Science, 19(4), 339-347

Tamietto, M., \& de Gelder, B. (2010). Neural bases of the non-conscious perception of emotional signals. Nature Reviews Neuroscience, 11, 697-709.

Tirapu J., Pérez G., Erekatxo M., \& Pelegrín C. (2007) "Qué es la teoría de la mente"?. Revista de Neurología. 44, 479-89.

Todorov A., Mende-Siedlecki P., \& Dotsch R. (2013). Social judgments from faces. Current Opinion in Neurobiology. 23, 373380.

Tomasello M., \& Vaish A., (2013). Origins of Human Cooperation and Morality. Annual Review in Psychology, 64, 231-55.

Tsakiris, M., Prabhu, G., \& Haggard, P. (2006). Having a body versus moving your body: How agency structures body-ownership. Consciousness and Cognition, 15, 423-432.

Tylén, K., Allen, M., Hunter, B. K., \& Roepstorff, A. (2012). Interaction vs. observation: distinctive modes of social cognition in human brain and behavior? A combined fMRI and eye-tracking study. Frontiers in
Human Neuroscience. 6, 331. doi: 10.3389/ fnhum.2012.00331

Uddin, L. Q., Iacoboni, M., Lange, C., \& Keenan, J. P. (2007). The self and social cognition: the role of cortical midline structures and mirror neurons. Trends in Cognitive Science, 11, 153-157. doi: 10.1016/j.tics.2007.01.001

Umiltà, C., (2007). Consciousness and Control of Action. En Zelazo, Moscovitch \& Thompson. The Cambridge Handbook of Consciousness. Cambridge University Press.

van Leijenhorst, L. \& Crone, E. A. (2009). Paradoxes in adolescent risk-taking. In: Zelazo, P. D, Chandler, M. \& Crone, E. A. (Eds). Developmental Social Cognitive Neuroscience. Psychology Press.

van Leijenhorst, L., Gunther Moor, B., Op de Macks, Z.A., Rombouts, S.A.R.B., Westenberg, P. M., \& Crone, E.A. (2010). Adolescent risky decision making: Neurocognitive development of reward and control regions. Neurolmage, 51, 345-355.

Voos, A. \& Pelphrey, K. (2013). Decety, J., \& Michalska, K. J. Developmental neuroscience of social perception. In P. Rakic and J. Rubenstein (Eds.), Comprehensive Developmental Neuroscience. Oxford: Elsevier.

Walter NT, Montag C, Markett S, Felten A, Voigt $G$, \& Reuter M. (2012). Ignorance is no excuse: moral judgments are influenced by a genetic variation on the oxytocin receptor gene. Brain Cognition, 78:268-273.

Wang J., Nicol T., Skoe E., Sams., \& Kraus N., (2010). Emotion and the auditory brainstem response to speech. Neuroscience Letters 469, 319-323.

Wiese, H., Kache,l U., \& Schweinberger, S., (2013). Holistic face processing of own- and other-age faces in young and older adults: ERP evidence from the composite face task. Neurolmage 74, 306-317.

Wimmer, H., \& Perner, J. (1983). Beliefs about beliefs: Representation and constraining functions of wrong beliefs in young children's understanding of deception. Cognition, 13, 103-128. 
White, S. F., Brislin, S., Sinclair, S., Fowler, K. A., Pope, K., \& Blair. R. J. R. (2013). The relationship between large cavum septum pellucidum and antisocial behavior, callousunemotional traits, and psychopathy in adolescents. Journal of Child Psychology and Psychiatry, 54, 575-581.

Wu N, Li Z, \& Su Y. (2012). The association between oxytocin receptor gene polymorphism (OXTR) and trait empathy. Affective Disorders 138 (3), 468-72. doi: 10.1016/j.jad.2012.01.009.

Wu Y., Zang Y., Yuan B., \& Tian X., (2015). Neural correlates of decision making after unfair treatment. Frontiersin Human Neuroscience. 9, 123.

Young L., \& Dungan J., (2012). Where in the brain is morality? Everywhere and maybe nowhere. Social Neuroscience, 7:1, 1-10. http://dx.doi.org/10.1080/17470919. 2011.569146 .

Zaki, J., Hennigan, K., Weber, J., \& Ochsner, K. N. (2010). Social cognitive conflict resolution: contributions of domain-general and domain-specific neural systems. Journal of Neuroscience, 30, 848188

Zhen Z, Fang H, \& Liu J., (2013). The Hierarchical Brain Network for Face Recognition. PLoS ONE, 8(3): e59886. doi:10.1371/journal.pone.0059886

Zuberbuhler K., (2008). Gaze following. Current in Biology, 18, 453-455. Doi: 10.1016/ j.cub.2008.03.015.

\section{Notas}

* Artículo de revisión

2 Del inglés occipital face area.

3 Del inglés fusiforme face area.

4 En la literatura se usa el término mirroring, su traducción literal al castellano es reflexión, sin embargo esta palabra tiene un uso más común como la acción de reflexionar y no de reflejar, por ello en adelante se usará el concepto resonancia como un equivalente al concepto de reflexión, el cual hace alusión a la habilidad de reflejar acciones de los demás.

5 El ritmo $m u$ es un tipo de onda cuya frecuencia se encuentra entre 9 y $11 \mathrm{hz}$, la cual ha sido reportada en situaciones de ausencia de movimiento motor, la cual es suprimida cuando se ejecutan acciones voluntarias (Coll et al, 2014).

6 La sigla DMN hace referencia a la default mode network.

$7 \quad$ Early related negativity

8 Feedback related negativity 